whom $8 \%$ developed major depressive illness during the year before the interview. ${ }^{12}$ After controlling for gender and family history of depression multivariate analysis indicated the importance of both job factors (lack of intrinsic rewards, conflict at work, and unclear job responsibilities) and home factors (marital strain and psychiatric disorder in spouse). Of the work environment the authors wrote, "Prevention and lasting remediation are most likely to result from bringing about positive changes in the cultural patterns characterising the business world. Such changes might attempt to strike a better balance between narrowly defined economic interests of the firm and broader humanistic concern for the mental and emotional needs of workers and their families."

With the current changes occurring in the NHS it is appropriate to consider whether similar factors affect its workforce-2.1 million days are apparently lost each year through mental disorders. ${ }^{1}$ Radiographers, dentists, nurses, and doctors all feature in the top 14 jobs with a raised standardised mortality for suicide. It is less well recognised that the standardised mortality ratio for doctors' spouses is 275.5 Most other research has concerned the doctors themselves.

Surveys with the general health questionnaire have shown alarmingly high scores among junior house officers: $50 \%$ showed emotional distress, $28 \%$ had scores indicating possible depressive illness, and $6 \%$ had thoughts of suicide. ${ }^{13}$ The stressors most closely correlated with these symptoms included overwork, effect of work on personal life, relationship with consultant, and clinical decision making.

Stresses documented in general practitioners include night calls, emergencies during surgery hours, and interruption of family life. ${ }^{14}$ In this context clearly the separation of "job" and "home" stressors is artificial, and future studies need a comprehensive assessment of both.
Fortunately, the US employee assistance programmes and a recent scheme in the Post Office have shown the financial benefits of providing help for those experiencing stress at work, which should encourage the adoption of such schemes by large employers such as the NHS. ${ }^{1}$ The recent research commissioned by the Department of Health on stress and the NHS workforce should identify more clearly than hitherto the job stresses at all employment grades, with a view to identifying where the work environment needs to be changed and where the adoption of employee assistance schemes might be most cost effective.

\section{FRANCIS CREED}

Professor

University Department of Psychiatry,

Manchester Royal Infirmary,

- Manchester M13 9WL 1 Jenkins $\mathrm{R}$, Coney N, eds. Prevention of mental ill health at work. A conference. London: HMSO,
1992.

2 Cherry N. Stress, anxiety and work: a longitudinal study. Joumal of Occupational Psychology 1978;51:259-70.

3 Warr PB, Payne RL. Experiences of strain and pleasure among British adults. Soc Sci Med 1988;61:1691-7.

4 Fletcher B. Occupation, marriage and disease specific mortality concordance. Soc Sci Med 1988;27:615-22.

5 Fletcher B, Jones F. Stress at work. In: Raffle RAB, Adams P, Baxter P, Lea WR, eds. Hunter's diseases of accupation. 8th ed. London: Edward Amold (in press).

6 Stansfeld SA, Marmot MG. Social class and minor psychiatry disorder in British civil servants: a

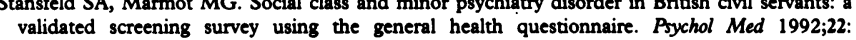
validated $739-49$.

7 Marmot MG, Smith GD, Stansfeld S, Patel C, North F, Head J, et al. Health inequalities among British civil servants: the Whitehall 11 study. Lancet 1991;337:1387-93.

8 Davidson MJ, Cooper CL. Stress and woman manager. Oxford: Martin Robertson, 1983.

9 Payne R. Individual differences in the study of occupational stress. In: Cooper CL, Payne R, eds. Causes, coping and consequences of stress at work. Chichester: John Wiley, 1988:209-32.

10 Bigos SJ, Battic MC, Spengler DM, Fisher LD, Fordyce WE, Hansson PH, et al. A prospective study of work perceptions and psychosocial factors affecting the report of back injury. Spine 1991;16:1-6.

11 Nielsen E, Brown G, Marmot M. Myocardial infarction. In: Brown GW, Harris T, eds. Life events and illness. New York: Guildford Press, 1989:313-42.

12 Phelan J, Schwartz JE, Bromet EJ, Dew MA, Parkinson DK, Schulberg HC et al. Work stress, family stress and depression in professional and managerial employees. Psychol Med
1991;21:999-1012.

13 Firth-Cozens J. Emotional distress in junior house officers. BMF 1987;295:533-6.

14 Sutherland VJ, Cooper CL. Job stress, satisfaction, and mental health among general

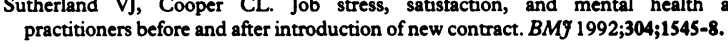

\title{
"Self referral": a potential conflict of interest
}

\section{The GMC should produce tighter guidelines}

The break up of the NHS into discrete independent units has produced more entrepreneurial activity in an attempt to increase patient flows and "profit." A government that encourages commercialism in medicine should not be surprised to see comments in the medical press such as "Shares in laser centre selling fast" and comments like "GP fundholders are channelling $43 \%$ of their inpatient work through their own limited companies."

In private practice the relation between an episode of care and the fee that it attracts should be crystal clear to the patient. But this may become obscured when a doctor owns part of a facility and refers patients to it, thus increasing profit, without the patient being aware of a potential conflict of interest. Experience of this "self referral" is greater in the United States. In Florida one study showed that over $40 \%$ of doctors directly providing care had financial interests in health care businesses to which they could refer their patients for services, a large proportion of these being diagnostic imaging centres. ${ }^{3}$

Self referral significantly increases the costs of health care. A Californian study showed that doctors who referred patients to facilities that they owned initiated physical treatments 2.3 times more often than doctors who referred patients to independent facilities; for the self referral group the total cost of psychiatric evaluation per case was $26 \%$ higher. Of magnetic resonance imaging scans requested by self referring doctors, $38 \%$ were clinically inappropriate compared with $28 \%$ of scans requested by doctors without a financial stake in the imaging centre. ${ }^{4}$ Another American study found that doctors who used imaging equipment in their offices obtained investigations 4.5 times more often than doctors referring through a radiologist and, as self referring doctors charged more, the total bill was up to 7.5 times higher. ${ }^{5}$

Responding to this and other information, ${ }^{6-9}$ the council on ethical and judicial affairs of the American Medical Association has published detailed guidelines. ${ }^{10}$ These state that doctors should disclose any relevant financial interests to patients when referring them. Patients should be given a list of alternative facilities and be assured that choosing one in which the doctor has no financial interest will not affect their medical care. Financial interests also have to be disclosed to a third party payer.

In Britain the General Medical Council has stated that "where doctors have a financial interest in an organisation to which they propose to refer a patient for admission or treatment, whether by reason of a capital investment or a remunerative position, they should always disclose that they 
have such an interest before making the referral." Does this happen in practice?

Occasions arise when doctors can provide privately services that the NHS cannot fund, but comprehensive guidelines are needed for these because of the ethical issues that they raise. In view of the changing nature of medical practice in Britain the General Medical Council should assess the effectiveness of its current recommendation and consider updating it along the lines of the American model.

PETER WILKINSON Consultant physician

Ashford Hospital,

Ashford TW15 3AA
1 Stride R. Shares in laser centre selling fast. Hospital Doctor 1992 Jan 28: 24.

2 Butler P. Stressed GP fundholders mind their own business. Health Service Journal 1992 Jan 28: 7.

Mitchell JM, Scott E. New evidence of the prevalence and scope of physician joint ventures. ЭAMA 1992;268:80-4.

4 Swedlow A, Johnson G, Smithline N, Milstein A. Increased costs and rates of use in the California workers' compensation system as a result of self-referral by physicians. $N$ Engl $\mathcal{F}$ Med 1992;327:1502-6.

5 Hillman BJ, Joseph CA, Mabry MR, Sunshine JH, Kennedy SD, Noether M. Frequency and costs of diagnostic imaging in office practice-a comparison of self-referring and radiologistreferring physicians. N Engl F Med 1990;323:1604-8.

6 Iglehart JK. The debate over physician ownership of health care facilities. $N$ Engl $f$ Med 1989;321:198-204.

7 Iglehart JK. Efforts to address the problem of physician self-referral. $N$ Engl $f$ Med 1991;325:1820-4.

8 Crane TS. The problem of physician self-referral under the Medicare and Medicaid antikickback statute. ЭAMA 1992;268:85-91.

9 Relman AS. "Self-referral"—what's at stake? N Engl I Med 1992;327:1522-4.

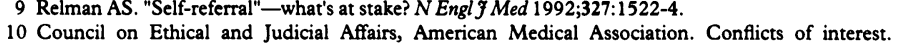
Physician ownership of medical facilities. $3 A M A$ 1992;267:2366-9.

11 General Medical Council. Professional conduct and discipline: fitness to practise. London: GMC, 1992.

\section{Does cimetidine cause weight loss?}

\section{Confounded expectations result in a conflict of evidence that is simply baffling}

The ideal topic for a young researcher is one in which recent publications in peer reviewed journals have come to mutually incompatible conclusions. The tyro researcher is then presented with a ready made protocol and an expectation that a replication of the study will support paper $A$ and refute $B$, or vice versa, or (more probably) reach an intermediate conclusion which throws some light on the reason for the conflict in results. Such a situation arises in this issue of the $B M F$.

Paper A, by Støa-Birketvedt on p 1091, reported the outcome in 30 overweight subjects given $200 \mathrm{mg}$ cimetidine as a suspension three times a day 30 minutes before meals, together with a fibre supplemented diet designed to supply $5 \mathrm{MJ}(1200 \mathrm{kcal}) /$ day and 30 well matched controls given the same diet but a placebo suspension. The mean (SD) weight loss over the next eight weeks was $9.5(2 \cdot 1) \mathrm{kg}$ in the treated group but only $2.2(1.3) \mathrm{kg}$ among the controls. ${ }^{1}$ Paper B, however, by Rasmussen et al on p 1093, reports a replication of the study in paper $A$, in which the authors found no significant difference in weight loss between the cimetidine and placebo groups $\left(5.7 \mathrm{~kg}\right.$ and $5.9 \mathrm{~kg}$ respectively). ${ }^{2}$ Paper B suggests that the results in A may have arisen because the subjects were not really blind to the medication taken: this may be so, but it does not resolve the problem. A mean loss of $9.5 \mathrm{~kg}$ in eight weeks is a remarkably good result, and if such weight loss could be achieved by simply telling patients they were on cimetidine that would be a therapeutic triumph.

In this situation an experienced editor may suspect that there is something wrong with the experimental data, but $\mathrm{Dr}$ Støa-Birketvedt has been commendably frank and generous in making the raw data available for examination. (The data and the patients have also been re-examined by a committee at Oslo University and confirmed to be accurate.) The results are correctly calculated and do not arise as a result of selective attrition. Papers about the treatment of obesity often fail to take account of the fact that the mean weight given for a group of patients at different points in time may refer to an ever diminishing cohort. As less successful weight losers drop out there is a false appearance of continuing weight loss in the group. Paper A started and finished with 30 patients in each group, so selective attrition cannot explain these findings.

The individual data on which paper $A$ is based show a remarkable uniformity of weight loss between individuals in each treatment group and also within individuals from week to week. Both features are hard to explain. Among groups of overweight people weight loss is usually more rapid in the first week of dieting than subsequently, probably because naive dieters lose glycogen stores with associated water first during the dieting period, and more energy dense fatty tissue later. ${ }^{3}$ This effect is seen in the results of paper B, but not paper A, in which the mean weight loss was the same in the first two weeks of cimetidine as in the last two weeks. Another expected effect not seen in the results of paper $A$ is that individuals with a higher initial weight show a greater weight loss than those with a lower initial weight. The mean weight loss in the five heaviest people, who initially weighed more than $90 \mathrm{~kg}$, was only $0.5 \mathrm{~kg}$ greater than that in people who initially weighed less than $70 \mathrm{~kg}$, whereas a difference of at least $2 \mathrm{~kg}$ in weight loss would be expected. Finally, the absolute weight loss among the cimetidine group in paper $\mathrm{A}$ is surprisingly high, and that of the control group surprisingly low, while the mean $5.8 \mathrm{~kg}$ loss in eight weeks in paper B is what might be expected in well supervised subjects with an initial body mass index (weight $(\mathrm{kg}) /$ height $(\mathrm{m})^{2}$ ) of 34 and a diet designed to supply $5 \mathrm{MJ} /$ day. It remains baffling that cimetidine and placebo should have such different effects in Norway and Denmark.

JOHN GARROW

St Bartholomew's Hospital Medical College,

Rank professor of human nutrition

London EC1M 6BQ

1 Støa-Birketvedt G. Effect of cimetidine suspension on appetite and weight in overweight subjects. BMF 1993;306:1091-3.

2 Rasmussen MH, Andersen T, Breum L, Getzsche PC, Hilsted J. Cimetidine suspension as adjuvant to energy restricted diet in treating obesity. $B M \mathcal{F}$ 1993;306:1093-6.

Garrow JS, Webster JD. Effects on weight and metabolic rate of obese women of a $3.4 \mathrm{MJ}$ (800 kcal) diet. Lancet 1989;i:1429-31. 